\title{
ARTÍCULO
}

\section{EL DISCURSO DE LA DIVULGACIÓN Y LA VOCACIÓN CIENTÍFICA Y FILOSÓFICA}

The discourse of dissemination and the scientific and philosophical vocation

Adolfo Israel Flores Ramírez

Dirección General de Bachillerato

polemospater@hotmail.com

DOI: https://doi.org/10.38128/cienciayfilosofa.v4i4.23

Resumen.

Reflexionar sobre la vocación científica, sobre el interés hacia las ciencias no es una actividad que debiera tomarse a la ligera. En las siguientes líneas se presenta una reflexión sobre el discurso de la divulgación científica y filosófica y el conocimiento que se transmite en el discurso divulgador y cómo éste incide en el despertar de la vocación científica y filosófica. Palabras claves: Filosofía, Discurso, Ciencia, Divulgación, Vocaciones

\section{Abstract}

Reflecting on the scientific vocation, on the interest in science is not an activity that should be taken lightly. The following lines present a reflection on the discourse of scientific and philosophical dissemination and the knowledge that is transmitted in the dissemination discourse and how it affects the awakening of the scientific and philosophical vocation.

Keywords: Philosophy, Speech, Science, Disclosure, Vocations

Enviado: 30.11:2020

Aprobado: 14.12:2020 


\section{Discurso divulgador.}

Para despertar la vocación científica, los diferentes esfuerzos por divulgar la ciencia tienen un papel importante. Los museos de ciencia, las revistas de divulgación científica, las cápsulas radiofónicas de ciencia y una buena cantidad de actividades relativas a la divulgación científica tienen como objetivo despertar la vocación científica de su audiencia (considerar que la audiencia no es el científico sino el público lego) No es un dato menor que en el periodo de la pandemia originada por el COVID 19 por ejemplo la Dirección General de Divulgación de la Ciencia de la UNAM, celebró que las visitas a sus sitios de divulgación por internet se ha incrementado en varios millones de visitas (redes sociales, páginas web etc) Es decir, hay una importante incremento en el interés por la divulgación de la ciencia. Cabe preguntar si esto significa que hay un incremento de personas en las que se ha despertado la vocación científica.

La divulgación científica tiene como uno de sus propósitos despertar la vocación científica del público meta al que va dirigido (también llamado público lego o público inexperto) en las siguientes líneas se pone como objeto de reflexión la divulgación (de la

ciencia y la filosofía) y la vocación científica y filosófica, centrando el interés en el discurso de la divulgación. La vocación filosófica, que también se fomenta por vía de la divulgación merece tomarse en cuenta. La definición de divulgación y comunicación pública de la ciencia, así como los propósitos y objetivos de las mismas se pueden encontrar en la página de la DGDC de la UNAM y también existen versiones propias en la página de la FECYT. Entre los objetivos de la divulgación científica se puede encontrar que uno de suspropósitos es despertar la vocación científica. Aquí aparece un tema importante para quien busca hacer divulgación de la filosofía o divulgación de la ciencia o ambas. Y es que lograr que la ciencia o la filosofía llame la atención a los niños -aunque también a jóvenes y adultos- no es un tema menor, sino un tema importante cuando se reflexiona sobre la divulgación de la ciencia y la filosofía. Y aunque son múltiples los factores que influyen para alcanzar este objetivo, este documento se centra en una reflexión acerca de la naturaleza del discurso divulgativo. Para plantearlo en forma de pregunta ¿Cuál es la naturaleza del discurso divulgativo? 
La divulgación de la filosofía se comunica por vía de diversos medios como pueden ser comics, películas, libros y revistas de divulgación, programas radiofónicos etc. muchos de los medios empleados son los mismos que se emplean en la divulgación de la ciencia. En los hechos existen diversos medios, en el fondo se busca persuadir que la ciencia y la filosofía (y otros conocimientos) son importantes. ¿En dónde radica la capacidad de persuasión del discurso divulgativo si es que la tiene? ¿Cómo puede el discurso divulgativo fomentar, desarrollar o despertar la vocación filosófica? La misma pregunta cabe para la divulgación de la ciencia. Puesto que los medios para divulgar tanto temas de ciencia como temas de la filosofía (y de otras áreas de conocimiento) son tan diversos, algo debe subyacer a todos estos medios y a todos estos actos de comunicación. Lo que subyace en ellos es el discurso divulgativo. Dicho discurso pretende ser un discurso racional, dirigido a hombres racionales. En el quehacer del divulgador de la ciencia o del divulgador de la filosofía o de cualquier otro campo de conocimiento se busca llevar a cabo un acto de comunicación de conocimiento. Pero tanto en la divulgación de la filosofía como en la divulgación de la ciencia se transmite conocimiento que bien podría ser teórico o práctico o ambos pero además se transmite conocimiento emancipador.

\section{Conocimiento emancipador.}

El conocimiento emancipador que el discurso divulgativo tiene el potencial de transmitir, no necesariamente contrasta con el despertar la vocación científica o filosófica, aunque el discurso divulgador, diseminador o populizador puede ser retórico en su intento por enganchar a su receptor, esto es, en su esfuerzo por generar interés por la ciencia o la filosofía. En la construcción de este discurso de divulgación, el divulgador pone en práctica lo opuesto de lo que se enseña en la academia (tanto en la instrucción filosófica como en la instrucción científica) Ahí se enseña que "el filósofo debe evitar argumentar apoyándose en la «opinión»"1 Esta regla que es válida para el discurso académico no tendría que ser válida para el discurso de la divulgación, y con ello la divulgación gana libertad de acción que puede traducirse en creación, la libertad de creación de nuevos sentidos. Las fuentes pueden

\footnotetext{
1 José Antonio Hernández Guerrero, María del Carmen García Tejera, en Aristóteles y la Retórica, disponibleen Cervantes virtual. http://www.cervantesvirtual.com/portales/retorica_y_poetica/aristoteles/
} 
encontrarse en los autores clásicos. En el caso de Aristóteles, quien defiende que la «opinión», objeto de la Retórica, no es una mera sombra deformante de la verdad, sino una verdadera manifestación de la realidad" 2 El uso de la retórica para crear el discurso divulgador y transmitir conocimiento emancipador, es decir, usar la retórica sin miramientos es válido para despertar la vocación científica y filosófica.

Para comprender la vocación filosófica, también se pueden consultar ideas de filósofos mexicanos como José Vasconcelos que dice a propósito de la vocación filosófica, que el filósofo es creador de cultura (...) La filosofía no se reduce al manejo de los conceptos (...) [y más adelante agrega que] El espíritu tiene confianza en la libertad.(Vasconcelos, 1949: 594 ss) En el discurso de la divulgación hay pues una actitud creadora, pero a diferencia de la creación académica, la creatividad es libre de elegir el uso de la retórica para persuadir, para manifestar la realidad, para emanciparse y despertar vocaciones científicas, filosóficas o de cualquier otra índole que le deje al hombre un espacio de libertad.

\section{Conclusiones.}

El impulso a la vocación científica y a la vocación filosófica debería comenzar desde la infancia, visitando museos de ciencia, escuchando cápsulas de ciencia y filosofía para niños, Acercándose a las actividades que los profesionales de la divulgación diseñan para llevar el conocimiento al público lego y es que la divulgación de las ciencias y la divulgación filosófica tienen un papel importante como detonadores de pensamiento, como transmisores de conocimiento emancipador. Por ello es importante la formación de expertos en crear discursos divulgativos tanto de la ciencia como de la filosofía, abrir espacios de formación en el que se conjuguen conocimientos sobre retórica, sobre lógica, sobre ciencia, filosofía y pedagogía que permitan profesionalizar la divulgación científica y filosófica. Conjuntar los estándares, los valores y los objetivos propios de la divulgación, que no necesariamente tendrían que ser los mismos valores y los mismos propósitos de la academia y la investigación. Y no se trata de fomentar un todo vale con tal que la gente se interese en la

\footnotetext{
$\overline{2}$ José Antonio Hernández Guerrero, María del Carmen García Tejera, en Aristóteles y la Retórica, disponibleen Cervantes virtual. http://www.cervantesvirtual.com/portales/retorica_y_poetica/aristoteles/
} 
ciencia y en la filosofía (o en algún otro campo de conocimiento) la creación de estos espacios debe ser rigurosa, ordenada y sistematizada.

\section{Bibliografía}

Calvo M. El nuevo periodismo de la ciencia. CIESPA, Quito Ecuador 1999

Fundación española para la ciencia y la tecnología. PLAN ESTRATEGICO DE FECYT 2019-2022. https://www.fecyt.es/es/info/objetivos-estrategicos

Habermas J. Conocimiento e interés. Editorial Taurus 1992

Hernández J. Retórica y poética en Aristóteles. En biblioteca virtual Miguel de Cervantes

UNAM. Dirección General de Divulgación de la Ciencia

Vasconcelos J. La filosofía como vocación y como servicio. Actas del Primer Congreso

Nacional de Filosofía, Mendoza, Argentina, marzo-abril 1949, tomo 1. 